\title{
Preface to the special collection of theoretical chemistry accounts in honour of Péter R. Surján
}

\author{
Ágnes Szabados $^{1} \cdot$ Mihály Kállay $^{2} \cdot$ Péter G. Szalay $^{1}$
}

Published online: 31 December 2015

(C) Springer-Verlag Berlin Heidelberg 2015

This collection of papers presents a special cross section of recent advances in Theoretical Chemistry. It gives a fingerprint of the scientific interest of Péter R. Surján, contributors having either interacted with him and/or working on topics closely related to his expertise.

A study on optical rotatory strength calculation, published in 1980 in Theoretica Chimica Acta, marks the beginning of the documented scientific career of Péter R. Surján. His interest has always been shared between fundamental problems in electronic structure theory and theoretical applications in material structure research. Localizability of electron pairs and weak intermolecular interactions were his first research topics besides characterization of conjugate polymers by semiempirical methods. During his visit at the Memorial University of Newfoundland, St. John's, Canada, he started lecturing on the theory of second quantization, applied in quantum chemistry. This was the origin of the book titled "Second Quantized Approach to Quantum Chemistry", published by Springer in 1989. The easy to follow elaboration of a complicated subject is characteristic not only to this book but also to the lectures he has been giving at the Eötvös Loránd University

Published as part of the special collection of articles "Festschrift in honour of P. R. Surjan".

Ágnes Szabados

szabados@chem.elte.hu

1 Laboratory of Theoretical Chemistry, Institute of Chemistry, Eötvös Loránd University, P.O. Box 32, Budapest 1518, Hungary

2 MTA-BME Lendület Quantum Chemistry Research Group, Department of Physical Chemistry and Materials Science, Budapest University of Technology and Economics, POB 91, Budapest 1521, Hungary
(ELTE) of Budapest, Hungary, since 1991. Working as a professor at ELTE, he pursued his long-term investigations on the theoretical characterization of the chemical bond by geminal wave functions as well as on model Hamiltonians for the description of pi-electron systems. He also extended his research activity to the field of many-body methods, Green's function theory, electronic excited states and linear scaling methods in quantum chemistry.

The research work of Péter R. Surján is characteristically rich in scientific interactions. He has been a successful Ph.D. advisor, raising generations of graduate students. He has also been actively cooperating both on the national and international level and was proud to host his distinguished colleagues at his laboratory in Budapest. This collection was initiated by students and colleagues of Péter R. Surján, on the occasion of his reaching 60. It is not intended to be a celebration, however. It is rather a tribute to the colleague and the friend. But mostly, it is a snapshot of current research in quantum chemistry. The Editors of this Collection strongly hope that the reader will find these papers instructive and inspirational. Tolle, lege et procede!

Budapest, 7 November, 2015. 